Quim. Nova, Vol. 36, No. 4, 600-606, 2013

\title{
A ABORDAGEM DE QUESTÕES AMBIENTAIS: CONTRIBUIÇÕES DE FORMADORES DE PROFESSORES DE COMPONENTES CURRICULARES DA ÁREA DE ENSINO DE QUÍMICA
}

\author{
Carlos Alberto Marques* e Rejane Maria Ghisolfi da Silva \\ Centro de Ciências da Educação, Universidade Federal de Santa Catarina, CP 476, 88040-970 Florianópolis - SC, Brasil \\ Fábio Peres Gonçalves, Carolina dos Santos Fernandes e Fábio André Sangiogo \\ Centro de Ciências Físicas e Matemáticas, Universidade Federal de Santa Catarina, CP 476, 88040-970 Florianópolis - SC, Brasil \\ Anelise Maria Regiani \\ Centro de Ciências Biológicas e da Natureza, Universidade Federal do Acre, BR364 km 4, 69915-900 Rio Branco - AC, Brasil
}

Recebido em 27/7/12; aceito em 17/10/12; publicado na web em 18/2/13

\begin{abstract}
ADDRESSING ENVIRONMENTAL ISSUES: THE CONTRIBUTION OF TEACHER-TRAINERS OF CHEMISTRY TEACHING CURRICULAR COMPONENTS. This paper presents the results of a study involving current teachers of the chemistry teaching curricular components of twelve Chemistry licentiate courses at state universities in the South and South-east of Brazil. The aim was to analyse how these curricular components can work together to address environmental issues in Chemistry teacher-training. From analysis of the interviews, it can be ascertained for example that environmental themes in the curricular components analysed are treated with differing levels of intensity and perspectives, and in some cases, have a more illustrative character regarding chemistry concepts.
\end{abstract}

Keywords: initial teacher training; environmental questions; chemistry teaching.

\section{INTRODUÇÃO}

As discussões de problemas ambientais têm sido uma exigência da sociedade, muitas das quais têm resultado em "medidas políticas, jurídicas, técnico-científicas, institucionais e econômicas voltadas à proteção, recuperação e melhoria socioambiental"' (p. 17), algo que tem recebido apoio no âmbito educativo e também influenciado o desenvolvimento de áreas das Ciências da Natureza, juntamente com o seu ensino..$^{2-4}$ Portanto, também têm implicações para os processos de formação de professores de Química. As componentes curriculares integradoras da área de ensino de Química (Metodologia do Ensino de Química, Prática de Ensino de Química e análogas), entre outras, devido à sua natureza e função, podem auxiliar na aproximação entre conhecimentos científicos e situações cotidianas, especialmente as ligadas ao meio ambiente. É nesse cenário particular que se torna ainda mais necessária uma formação química que dialogue com situações dos contextos social, econômico e ambiental — por nós denominadas questões ambientais — com o envolvimento dos sujeitos da aprendizagem..$^{5-7}$

As várias componentes curriculares que historicamente constituem as licenciaturas podem variar em sua denominação, entre os próprios cursos e até mesmo em seus programas de conteúdo. ${ }^{8}$ Todavia, componentes curriculares integradoras devem basicamente estar ligadas à necessidade de garantir ao licenciando a apropriação de um conhecimento que é peculiar ao professor, ao qual Shulman ${ }^{9}$ denominou de conhecimento pedagógico do conteúdo. Segundo o autor, é esse tipo de conhecimento que diferencia o professor dos especialistas das diversas áreas do conhecimento. O profissional da docência necessita favorecer a apropriação do conhecimento científico pelos alunos. Portanto, esse conhecimento vai além do conhecimento do conteúdo disciplinar em si, situando-o na dimensão da componente curricular a ensinar. Tudo isso envolve conhecimentos sobre teorias pedagógicas e a utilização dos resultados de pesquisas em ensino de Química, entre outros aspectos. Estes elementos tornam

\footnotetext{
*e-mail: bebeto@ced.ufsc.br
}

as componentes curriculares integradoras muito importantes na articulação entre os conhecimentos científicos e pedagógicos, especialmente para a abordagem de assuntos ou temas ligados à realidade socioambiental.

Pesquisas mais recentes têm explorado as questões ambientais na educação superior em Química. ${ }^{10-12}$ Em pesquisa realizada junto a cursos de licenciatura em Química da região sul do Brasil, Leal e Marques ${ }^{13}$ buscaram identificar o enfoque dado aos problemas ambientais, tomando como parâmetro os princípios básicos da Química Verde (QV). Concluíram que nos programas das componentes curriculares analisadas praticamente inexistiam conteúdos que pudessem se articular com a prevenção de problemas que podem derivar desse processo.

Neste trabalho apresenta-se uma pesquisa que se concentrou na análise sobre como componentes curriculares integradoras de cursos de licenciatura em Química de Instituições de Ensino Superior (IES) públicas das regiões Sul e Sudeste do Brasil podem estar colaborando para a abordagem de questões ambientais no ensino de Química (no âmbito da formação docente). Portanto, a partir de uma abordagem qualitativa pretende-se contribuir para o enfrentamento de uma lacuna relativa à caracterização de possíveis contribuições dessas componentes curriculares na abordagem de tais questões no ensino de Química, tendo em vista certa predominância na literatura ${ }^{12,13}$ da caracterização da contribuição de componentes curriculares de conteúdo específico (Química Orgânica, Química Inorgânica e análogas) e das de natureza ambiental, particularmente da Química Ambiental,,$^{2,513-15}$ na abordagem de tais questões.

\section{PROCEDIMENTOS METODOLÓGICOS}

Este trabalho constitui pesquisa maior em que foram analisadas ementas e planos de ensino de 321 componentes curriculares de 12 cursos de licenciatura em Química, de 9 IES públicas das regiões Sul e Sudeste do Brasil, buscando indicadores (nos objetivos, programa e referências) sobre o propósito de abordar aspectos ambientais em sala de aula. Tal análise englobou, portanto, todas as componentes 
curriculares desses cursos, ou seja, as de conteúdos específicos de Química, as da área de Ensino de Química e aquelas que possuíam em sua denominação o adjetivo ambiental, ou afim. Dessa análise foram selecionadas 53 componentes curriculares (53/321 ou 15\%) distribuídas (não uniformemente) entre todos os cursos das IES consideradas, sendo 10 componentes curriculares integradoras (cerca de 20\%), 28 (cerca de 52\%) de conteúdos específicos e 15 (28\%) de componentes curriculares com o adjetivo ambiental (ou afim) na sua denominação. Posteriormente, foram realizadas entrevistas semiestruturadas com 22 professores, cuja composição amostral foi delimitada considerando: a disponibilidade dos docentes para as entrevistas; a convergência de agendas do pesquisador e dos vários docentes de uma mesma IES (otimização no tempo e de recursos do projeto); entrevistar quando possível pelo menos um professor de cada componente curricular em cada uma IES/Curso, considerando a não uniformidade na distribuição das componentes curriculares pré-selecionadas (53) nas IES (9) e, por fim, a necessária exclusão para entrevista do docente que fosse membro deste projeto de pesquisa.

Considerando tais critérios e por questões de espaço, aqui reportamos somente a análise das entrevistas semiestruturadas efetuadas com $6(60 \%)$ formadores atuantes em componentes curriculares integradoras e afins, que nos documentos curriculares indicavam explorar a abordagem de questões ambientais no ensino de Química. Estes entrevistados, sem desconsiderar a dinamicidade da atuação docente, no conjunto lecionam em pelo menos 6 cursos de Licenciatura em Química. Todos os entrevistados receberam um convite formal para a entrevista no qual se assinalavam os objetivos e usos dos resultados da pesquisa. A entrevista foi gravada em áudio e ocorreu com o consentimento livre e esclarecido. Salienta-se que a denominação das componentes curriculares em que os docentes atuam não foi inserida, pois às vezes são tão específicas de uma determinada instituição que daria indicativos do docente entrevistado.

Os textos das entrevistas foram analisados seguindo os procedimentos da análise textual discursiva ${ }^{16}$ engendrada em três etapas. $\mathrm{Na}$ primeira, ocorre a fragmentação dos textos em unidades de significado que, posteriormente, na etapa de categorização, são agrupadas conforme semelhanças semânticas. Na etapa de comunicação são produzidos textos descritivos e interpretativos em cada categoria emergente, ${ }^{16}$ que, por sua vez, contém fragmentos representativos e exemplares das falas. A seguir são apresentadas e discutidas as categorias.

\section{Abordagem de questões ambientais por meio de temas}

A abordagem de temas vem sendo amplamente discutida e incentivada, principalmente no ensino de Ciências. ${ }^{17} \mathrm{O}$ diálogo potencializado pelos temas também contribui para o aluno se expressar e compartilhar com os demais as suas opiniões e visões de mundo.? Neste sentido, a importância da abordagem de questões ambientais enquanto tema na formação inicial de professores de Química foi evidenciada nas falas de formadores, em que a "contextualização", termo recorrente, é o fundamento para tal abordagem:

[...] eu acho um tema fundamental para ele [docente em formação] abordar no ensino médio, como tema de trabalho [...], também é um tema integrador no ensino médio que permite a ele abordar a química contextualizada (P03).

Os temas podem ter origem na demanda dos alunos ou na proposta dos professores. No caso do enfoque Ciência, Tecnologia e Sociedade (CTS), por exemplo, os temas são, em geral, vinculados a contextos mais amplos ou selecionados em função de conteúdos disciplinares. ${ }^{17}$ Mas, na literatura há trabalhos que articulam a perspectiva freireana de educação com a abordagem CTS, de modo a valorizar mais contextos específicos. ${ }^{17}$ Contudo, outro formador chama a atenção para as questões ambientais articuladas a temas transversais:

Nós temos duas linhas de trabalho que gostaríamos de explorar: uma delas é a linha mais tradicional onde o aluno é exposto a conceitos fundamentais e em cima desses conceitos nós criamos o que nós chamamos de temas transversais aonde as questões ambientais são as mais colocadas (P04).

Uma justificativa parece ser a influência das demandas governamentais, expressas em documentos oficiais ${ }^{6,18}$ que incentivam a exploração de temas transversais no ensino, bem como de exames de avaliação, em específico o Exame Nacional de Ensino Médio (ENEM), como expressa um entrevistado:

“[...] A própria questão do ENEM hoje remete isso, [...] trabalhar com temas, pelo tipo de questão que vem" (P02).

Já para outro docente, as questões ambientais "só vêm a partir de demanda dos alunos [licenciandos] [...] porque eles elegem nas revistas os temas que eles querem investigar" (P01), o que parece indicar que não há uma intencionalidade prévia em trabalhar com questões ambientais. O fragmento expõe um modo como a componente curricular pode ser constituída em sua dinâmica, evidenciando como os temas podem ser escolhidos pelos professores para serem abordados no ensino de Química. Isto é, os temas surgem "aleatoriamente" sem critérios explícitos para sua seleção, ao contrário da perspectiva freireana de educação, por exemplo, em que os temas surgem com uma efetiva participação da comunidade escolar e são constituídos de manifestações locais, de contradições maiores presentes na dinâmica social. ${ }^{19}$ Definido o tema, são selecionados os conteúdos necessários para a sua compreensão, que podem ser um modo de potencializar o entendimento de aspectos relacionados às questões ambientais.

Os exemplos de temas sugeridos pelos entrevistados parecem variar de acordo com o que cada um entende por questão ambiental e tema. Coelho, Marques e Delizoicov, ${ }^{20}$ para melhor compreender a adjetivação ambiental, refletiram sobre os entendimentos de meio ambiente de um conjunto de professores, considerando suas implicações no âmbito educacional e explicitaram duas abordagens: a naturalista, na qual o ser humano é excluído da concepção de meio ambiente, sendo considerado como referência e tudo o que está ao seu redor como meio ambiente; e a globalizante, em que há inclusão explícita da figura humana como parte desse meio.

A maioria dos formadores citou temas gerais, como o efeito estufa, o aquecimento global, a poluição, a reciclagem, o reuso e a redução. Um docente considerou a abordagem de temas em uma perspectiva globalizante, como a problemática do câncer:

[...] mas, as questões vêm dos alunos, na situação-problema! Tem um ranço que poderia ser questionado: é o professor ou um grupo [quem] pensa no que seria um tema interessante [...], e a questão ambiental acaba aparecendo muito forte aí, mesmo que não tenha a intenção deliberada de fazer isso, porque o professor que pensar em algum tema de relevância aí é o que hoje tá muito na mídia, aí aparece a questão do efeito estufa que tem a ver como aquecimento global [...] Bom, por exemplo, até a questão do câncer que é um exemplo [...] a temática da Educação Ambiental acaba chegando [...] (P02).

Enfim, é possível apreender o estudo de questões ambientais no ensino de Química por meio de abordagens de temas. Entretanto, parece não haver, ao menos de forma explícita no discurso dos 
professores, predominâncias teórico-metodológicas acerca desse tipo de abordagem.

\section{Limites na abordagem de questões ambientais}

Apresenta-se um conjunto de possíveis limitações na abordagem de questões ambientais associadas ao ensino de Química na formação inicial de professores, e uma dessas, de acordo com um formador, seria adotar apenas um determinado enfoque nessas abordagens:

[...] Química Verde, bom, o que eu sei [...] é que ela não problematiza essas relações na sociedade [...] Mas, o que eu assisti [...] vai naquela aposta da Ciência e da Tecnologia ter a solução para as questões ambientais, sem mudar esse modelo que tá aí (P02).

O formador expõe o limite que é centrar a discussão sobre as questões ambientais somente no enfoque da QV que, de fato, não problematiza as relações de consumo mais amplas e que, com frequência, pode ter suas ações associadas com visões salvacionistas de Ciência e Tecnologia, ${ }^{21}$ como relata o investigado, ou ainda com entendimentos antropocêntricos em torno do meio ambiente..$^{22}$ Isso não significa desacreditar em possíveis contribuições do enfoque da QV na formação de professores de Química, ${ }^{2}$ sobretudo em componentes curriculares de conteúdo específico. Acrescenta-se também a importância de uma pluralidade teórica — e metodológica — no estudo das questões ambientais no ensino de Química. Por exemplo, tanto o viés da Educação Ambiental (EA) como o do enfoque CTS podem colaborar para a "problematização" dessas questões na formação do licenciando, o que requer, entretanto, a necessária "formação" do formador para o domínio de tais enfoques teóricos. Neste sentido, um formador expôs:

Se você tem alguém que trabalhe com Educação Ambiental dentro dum curso de licenciatura em Química eu acho que ele vai contribuir [...], como o outro que trabalhe com formação de professores ou que trabalhe no campo de História da Ciência. É natural que os departamentos que tenham essas contribuições se reflitam de alguma maneira no currículo, [mas] nós não temos isso [...], então era tamanha a dificuldade, eu tive que estudar a Educação Ambiental nessa disciplina (P03).

As limitações na formação pedagógica de docentes da educação superior, de modo geral, podem remeter para uma carência no estudo das questões ambientais no ensino de Química/Ciências com base em diferentes referenciais teóricos, como os recém-destacados. Sobre esta dificuldade relatada, o formador ainda complementa: "eu não conheço química ambiental, não tenho essa formação, eu chamei um colega da área de ambiental [...], mas aí também nós não conseguimos juntar, na primeira versão ele deu a metade do curso de química ambiental e a outra metade eu falei educação" (P03). Tais relatos possibilitam interpretar que a falta de experiências curriculares e de formadores que abordem questões ambientais no ensino de Química pode ter como consequência a dificuldade de superar uma fragmentação excessiva no estudo desse assunto na licenciatura, que em um momento trata dos problemas ambientais relacionando-os ao campo da Química e, em outro, ao da Educação, permanecendo a problemática da formação em conteúdos específicos segmentada da formação para a docência. Soma-se à segmentação a acentuada prevalência da abordagem de conteúdos químicos:

A gente não conseguiu colocar né [a disciplina A], porque aí tinham as necessidades do curso [...] $e$ as específicas da licenciatura, por isso tem as 400 horas de estágio [...], nosso curso é pesado, também tem uma parte de Química bem pesada que a gente quer manter até pra não perder o aluno, porque senão ele acha que [...] não pode ter o $C R Q$ ele desiste no começo do curso, [...] então no nosso curso a gente não tem nada assim de Educação Ambiental (P03).

A emergência da QV e da Química Ambiental, por exemplo, são indicativos de que a formação do químico contemporâneo não pode se restringir às áreas mais clássicas da Química (Analítica, Inorgânica, Orgânica e Físico-Química). De outra parte, aprender somente os conteúdos de Química, que são imprescindíveis, é insuficiente para saber ensiná-los e para abordar as questões ambientais no ensino de Química. Estes aspectos são reconhecidos inclusive nas orientações oficiais para a formação de químicos e professores de Química. ${ }^{8,23}$ Por outro lado, a abordagem de questões ambientais na formação de químicos e de docentes em Química não precisa, como discutiremos mais adiante, estar restrita às componentes curriculares exclusivas.

Em síntese, podem ser múltiplas as limitações na abordagem das questões ambientais no ensino de Química. Reconhecê-las pode colaborar em sua superação, indicando possibilidades para tal empreendimento. E, do ponto de vista analítico, estas limitações não são interpretadas negativamente, mas sim como um ponto de partida para prováveis encaminhamentos no estudo das questões ambientais no ensino de Química na formação inicial de professores.

\section{A INFLUÊNCIA DAS DISCUSSÕES DE CARÁTER CIÊNCIA, TECNOLOGIA E SOCIEDADE E DA EDUCAÇÃO AMBIENTAL}

Notadamente, nas últimas décadas tem sido dada maior atenção para aspectos ligados a questões ambientais. A preocupação em abordar a temática ambiental disseminou-se no campo educativo com distintas vertentes, através de uma pluralidade de enfoques teóricos e metodológicos. Na voz dos formadores entrevistados duas perspectivas de abordagem se destacaram: o enfoque Ciência, Tecnologia e Sociedade (CTS) e a EA. Discussões sobre aproximações e distanciamentos entre CTS e a EA têm sido abordadas na literatura ${ }^{24}$ e podem colaborar para a formação de professores.

$\mathrm{Na}$ interpretação de parte dos formadores a temática ambiental não precisa estar explícita no objetivo das componentes curriculares, uma vez que o conhecimento químico contribui de forma significativa em discussões de questões ambientais. Por exemplo, quando se estudam aspectos vinculados às relações CTS:

[...] não tá no escopo da disciplina [...] quando eu vou tratar, por exemplo [...] ensino por temas ou interdisciplinaridade, ou ensino contextualizado, os alunos enxergam que questões ambientais que têm interface [...] com a Química, eles vão ser usados como exemplo [...]. Você vai falar de efeito estufa, vai falar de biodiesel, formas de energia e alternativas de energia, acaba sempre entrando nessas questões e quando a gente vai discutir CTS também, CTSA [...] a relação da Química com o meio ambiente é muito presente hoje (P03).

O fragmento sinaliza formas de abordar as questões ambientais nas componentes curriculares integradoras por meio de trabalho com temas em que o enfoque CTS/CTSA poderia contribuir para o trabalho na escola. O relato acima pode ser compreendido, em parte, pela atenção dada às questões ambientais pelo movimento CTS, desde a sua origem. Estudos $\mathrm{CTS}^{25}$ têm buscado compreender a dimensão social da Ciência e da Tecnologia, considerando tanto seus antecedentes sociais quanto as suas consequências sociais e ambientais. Nesta 
direção, um ensino de Química orientado pela perspectiva CTS pode levar à formação de sujeitos mais críticos, em especial no que tange a problemas de ordem social e ambiental.

Outro investigado acena discussões ambientais como decorrência de abordagens CTSA: [...] a partir do momento em que se trabalha com CTSA, entram fortemente as questões de ambiente, elas são fundamentais para se investigar a inserção da Química nessa realidade que na maioria das vezes só se vê como ambiental né? [...] (P05). Interpreta-se que a intenção do investigado em trabalhar com as questões ambientais está associada à escolha dos aportes teóricos e metodológicos por ele utilizados: abordagem CTSA. O que the possibilitaria explorar a vinculação entre ensino de Química e as questões ambientais.

$\mathrm{Na}$ fala de outro investigado emergiu uma compreensão de que as discussões CTS/CTSA não constituem obrigatoriamente objetivos das componentes curriculares. Sugere que o enfoque CTS/CTSA utilizado para a discussão de questões ambientais seja decorrente do contexto de atuação dos licenciandos, enfatizando que: "[...] isso depende de como é que vem essa demanda, por exemplo, no caso do estágio que a demanda vem da escola e eles tão preparando um trabalho pra escola, eu vou usar CTSA sempre [...]" (P01). Portanto, com base no exposto pelo formador, pode-se interpretar que a adoção do enfoque CTS é algo que depende, por exemplo, de perspectivas teóricas por ele assumidas ao orientar os licenciandos e não necessariamente de uma proposta curricular da formação inicial de professores.

Investigados também acenaram discussões envolvendo a temática ambiental à luz da EA:

[...] pra mim a maior questão ambiental é a fome. A exclusão social é um modelo de desenvolvimento que tá posto aí e que é degradante do meio ambiente e que o ser humano se degrada aí também. [...] problematizar isso nas aulas é uma forma de tá discutindo muito criticamente [...] "por que tem exclusão social e que modelo é esse que exclui" [...] Pensar na fome hoje como o maior problema ambiental é incluir o ser humano nessa questão e não naquela visão antropocêntrica (P02).

O trecho sinaliza um olhar para as questões ambientais que transcende aspectos vinculados à conservação e à preservação da natureza, entendida como "vida selvagem, flora e fauna". O investigado aponta fatores de ordem política, econômica, social e cultural ligados aos problemas ambientais aproximando-se de uma perspectiva de EA Crítica, defendida por Carvalho, ${ }^{26}$ para a qual o meio ambiente não é sinônimo de algo intocável, pelo contrário, o ambiente pode ser compreendido "como um campo de interações entre a cultura, a sociedade e a base física e biológica dos processos vitais, no qual todos os termos dessa relação se modificam dinâmica e mutuamente" (p. 37). Tal perspectiva busca compreender novas formas de interação dos seres humanos com o meio, de forma a apontar a necessidade de políticas públicas "orientando" esta relação "sociedade-ambiente". ${ }^{27}$

Nesta ótica, o entrevistado, além de apontar a necessidade de ultrapassar visões reducionistas ou unilaterais de EA que atentam somente para as questões de poluição do meio físico, sinaliza o caráter interdisciplinar da mesma:

Porque se a gente pensar a Educação Ambiental apenas, aî eu digo que é uma visão reducionista [...] apenas como temas de abordagem da poluição da água do rio, o tratamento de esgoto de uma cidade, o destino dos resíduos sólidos [...] se é lixão ao céu aberto, tratar a questão do lixo [...], a gente tá limitando um pouco [...]. Um professor de Português que tá trabalhando argumentação na sua sala de aula ou um professor de Química [...] que tenha um espaço para trabalhar expressão, diálogo ou outras coisas, eu já considero isso ambientalizar. Porque se tu pensares na Educação Ambiental como uma proposta de discutir mudanças na sociedade interferindo em alguns comportamentos, atitudes e valores que essa sociedade tem em relação ao meio ambiente, se tu pensares isso, isso não acontece se na [...] relação educativa não tiver essa abertura (P02).

O entrevistado dá exemplos ainda de aspectos ligados a visões comportamentais e atitudinais na EA:

Tu discutir lixo na escola é Educação Ambiental? É ótimo. Fazer campanha para juntar latinha de alumínio na escola, já não acho que é ótimo [...] mas dentro dessa complexidade aí, para aî! Campanha para juntar latinha pra quê? Ah!, para comprar uma bola para escola. Aí tu estás numa lógica que a gurizada vai querer que os pais comprem um monte de latinha no supermercado pra levar para escola. [...] Claro tem que respeitar esse movimento da escola [...]. Mas, a gente tem que ter um olhar que não é nisso que se aposta (P02).

O relato acena um elemento importante: a ideia da EA relacionada a ações comportamentais e atitudinais. ${ }^{26}$ Por exemplo, reciclar latinhas pode ser uma ação importante, no entanto, esperam-se atitudes mais amplas que possam efetivamente interferir na realidade, questionando sobretudo o consumismo. De acordo com Carvalho, ${ }^{26}$ existe distinção entre atitude e comportamento, pois as ações comportamentais não propiciam ações permanentes, ao contrário das aprendizagens atitudinais.

Em suma, as questões ambientais podem ser abordadas nos diferentes níveis de ensino a partir de distintos enfoques teóricos e metodológicos. Isso ressalta o caráter amplo dessa temática na educação, transcendendo as componentes curriculares e as perspectivas teóricas demarcadas.

\section{ABORDAGEM DE QUESTÕES AMBIENTAIS NÃO RES- TRITA À DISCIPLINARIDADE}

Tradicionalmente, os processos educativos pautam-se em perspectivas de ensino nas quais os conhecimentos são tomados de forma fragmentada, o que torna difícil a inter-relação deles. Ademais, o isolamento entre os diferentes campos de conhecimento e a incapacidade de articulá-los gera uma padronização curricular dos conteúdos na qual não se valorizam as relações dos conteúdos entre si e, tampouco, as relações destes com questões tecnológicas, sociais e ambientais.

Em uma prática de ensino com essas características, há poucas evidências de construção de significados que superem a hegemonia de campos de conhecimento que os isolam e fragmentam. ${ }^{28}$ Assim, têm surgido propostas que, avaliando como insatisfatórios os resultados dessas práticas, sugerem outra organização do conhecimento que supere a abordagem linear e fragmentada. Há uma preocupação dos formadores no sentido de o tratamento das questões ambientais não se caracterizar pelo isolamento disciplinar, mas como temas transversais, "assuntos que fazem parte das discussões dos diferentes segmentos da sociedade e que levam problemas cuja reflexão nos leva para além de um único campo de conhecimento"29 (p.107).

Formadores sinalizaram que as questões ambientais são relevantes e sugerem duas vias para explorá-las. Uma delas é a tradicional, que enfatiza os conceitos e articula com as questões ambientais. A outra apresenta temas transversais que possibilitam explorar os conceitos:

“...temos duas linhas de trabalho [...] a linha mais tradicional onde o aluno é exposto a conceitos fundamentais e em cima 
desses [...] criamos o que nós chamamos de temas transversais, aonde as questões ambientais são as mais colocadas, outra forma de trabalhar conceitos de Química é começando pelas [...] questões transversais porque elas de fato é que são o interesse do ensino médio (P04).

É perceptível a contrariedade no isolamento durante a abordagem das questões ambientais, ou seja, vai além da constituição de uma componente curricular ou da forma de focalizar os aspectos conceituais: "Então não é um problema químico, é um problema que transcende a Química" (P06). Já outros depoimentos sugerem, a exemplo do que segue, que a articulação dos conteúdos ao tema transversal meio ambiente assume um caráter político: “[...] o objetivo de ensinar Ciências pra um aluno do ensino médio é que ele seja capaz de perceber o mundo em volta dele, compreender como esse mundo funciona e se posicionar politicamente frente às mais diversas questões" (P04). A educação é um processo de natureza política, independente da vontade docente. ${ }^{19} \mathrm{O}$ trabalho com temas transversais pode favorecer uma prática transformadora em detrimento de um processo educativo puramente propedêutico e fragmentado, que contribui pouco para a constituição de visões de mundo mais amplas. Ou seja, o ensino de Química pode colaborar para os estudantes se apropriarem de um conhecimento sistematizado, que lhes possibilitará uma atuação crítica na sociedade em que se inserem.

Formadores apontaram caminhos para a efetivação das discussões sobre meio ambiente nas ações pedagógicas. Um deles é a elaboração de situações-problema, como no caso abaixo, o qual parece indicar uma perspectiva de superação de uma abordagem meramente disciplinar, de modo que tais situações sejam capazes de mobilizar os futuros professores na promoção de outros significados para as questões ambientais:

[...] a gente discute desde a questão da Ciência, a partir de alguns textos que colocam os cientistas como seres falíveis, não neutros que tomam decisões na questão nuclear [...] até eles [alunos] tomarem um posicionamento e justificarem se são favoráveis ou não do Brasil ampliar ou não seu programa nuclear. Daí a gente faz uma questão mais próxima, eu fiz. este ano que trabalhei com eles [...] que trouxessem [...] um posicionamento deles por escrito a respeito da usina nuclear que vai se instalar próximo ao [bairro] e isso vai ter um impacto [...] se não vier nós vamos ter problemas sérios de abastecimento energético (P02).

Outra forma de tratamento das questões ambientais no âmbito das componentes curriculares é a inserção da QV em atividades de ensino e pesquisa, envolvendo, por exemplo, o estudo e o emprego de técnicas químicas que reduzam ou eliminem o uso de solventes e reagentes na geração de produtos e subprodutos tóxicos ao meio biótico e abiótico:

[...] uma das coisas que eu levava [...] eram [...] os princípios da Química Verde, que era uma maneira de mostrar como a Química pode se rever diante das questões ambientais $e$ concepções que eles têm que ter já ao longo de todo processo de aprendizado deles e de atuação profissional (P03).

A preocupação com a inserção de questões da $\mathrm{QV}$, enfoque que não se reduz à disciplinaridade, ${ }^{30}$ não se restringe à formação do profissional que vai atuar na indústria, e o formador revela que o professor também necessita desse conhecimento.

Abordagens que não se restringem aos conteúdos de um só componente curricular explicitado pelos formadores pode contribuir para os futuros professores intervirem de forma crítica, baseada em uma perspectiva "problematizadora", no espaço escolar e na superação de propostas reducionistas que ignoram os aspectos culturais, sociais e econômicos, na caracterização de um currículo dos conflitos. ${ }^{31}$

\section{ABORDAGENS LOCALIZADAS DE TEMÁTICAS AMBIENTAIS}

Muito embora haja uma indicação formal de abordagem de questões ambientais no ensino de Química nos planos de ensino das componentes curriculares, entrevistados dão poucos exemplos ou situações localizadas e eventuais em que tais questões foram ou são trabalhadas:

[...] é comum dentro das atividades que os alunos desenvolvem nesta disciplina escolherem alguns temas que estão relacionados às questões ambientais, mas [...] não são tratadas explicitamente nessa disciplina, certo? Até pode sair no meio, quando você tá trabalhando ensino por temas ou interdisciplinaridade, cai este tema como exemplo (P03).

Relatos como este, possivelmente, decorrem de um ensino que não tem, em seu planejamento, preocupações em discutir no curso questões ambientais de forma explícita e permanente (transversalmente no currículo ou na componente).

Em outro relato, um docente apontou a abordagem de questões ambientais em monografia de conclusão de curso e no estágio:

Quando eu vou discutir isso [abordagem de bicombustível] no estágio, [...] para uma monografia [...], uma proposta de intervenção na escola, aí eu problematizo isso no diálogo. Aí eu digo [...] trabalha [com] esse texto aqui que mostra todo esse ciclo do bicombustível, vamos ver o que escreveu fulano sobre o Brasil entrar na questão do álcool para exportar e o que isso tá mexendo [...] já tá derrubando mata atlântica para plantar cana [...]? Isso já tá impregnado nesse discurso ambiental (P02).

A abordagem dessas questões também pode ser favorecida por componentes curriculares próprias para o estudo deste tópico, como comentou um formador:

[...] criei uma disciplina optativa [...] que tem uma interface com pesquisa ambiental, [...] usava o tema né? Quer dizer um poluente, propriedades poluentes, para discutir aspectos de Físico-Química, coeficiente de partição etc. [...] Agora as outras questões ambientais, [...] procurava assim trazer textos até da economia, [...], do pessoal de Educação Ambiental né! [...] (P03).

O formador expõe, através de um exemplo trabalhado em uma disciplina optativa, como são desenvolvidas atividades de resolução de problemas ambientais que visam introduzir ou resgatar conceitos químicos já estudados em outras componentes curriculares, além de introduzir discussões de outras áreas, como da economia e EA. Algo que parece sinalizar tanto uma carência de componentes curriculares obrigatórias como uma alternativa construtiva a currículos.

Há casos em que a abordagem de questões ambientais no ensino de Química é apresentada como subordinada aos conteúdos disciplinares da Química:

[...] nós fazemos, por exemplo, pequenas células elétricas ou pilhas, ou algo assim com materiais do cotidiano, nós 
acabamos discutindo energia, geração de energia, é forçado! Eu coloco a discussão pros alunos a partir do experimento, mas a partir daquela discussão de um aspecto, sei lá, de um experimento na disciplina, nós expandimos para outros aspectos, eu não sei se eu sigo alguma linha [...] a gente fala sobre as questões ambientais (P04).

Um dos formadores chamou a atenção para a necessidade de ouvir as compreensões discentes em torno de questões ambientais:

[...] eles pouco lidam com essa questão, reciclagem e reuso, eles simplesmente confundem, pegar garrafas PET e produzir um sofá. É reciclagem na cabeça deles, não! É reuso, enfim, de maneira muito tosca é colocar de volta no ciclo produtivo, nós precisamos colocar a questão, deixamos o aluno falar, porque eles têm muito a falar e eventualmente eu só acrescento algumas correções conceituais (P04).

A discussão das questões ambientais pode ser favorecida por estratégias, tais como a elaboração de material didático alternativo:

[...] colocamos explicitamente diversos tipos de produtos que os alunos podem desenvolver [...] desde jogos, softwares de computador, ou tradução de programas que já existam, diversas coisas, um dos tópicos principais que nós colocamos são resolver questões ambientais [...] para que os alunos tentem resolvê-las (P04).

Percebe-se uma heterogeneidade nos modos de como podem ser trabalhadas as questões ambientais, independente do enfoque teórico. Algo já salientado em resultados de pesquisa desenvolvidos por Marques e colaboradores ${ }^{32}$ que apontam a não menção, explícita, de perspectivas teóricas - a exemplo da EA e as articulações entre o ensino de Química e a QV, cujas perspectivas são múltiplas ${ }^{2,14,15}$ —em planos de ensino de componentes curriculares integradoras de cursos de licenciatura em Química.

Nos relatos, a abordagem de questões ambientais no ensino de Química aparece como objeto de discussão com diferentes enfoques. Estes aspectos são corroborados pelas discussões nas categorias precedentes. Isso, em certos casos, pode ser o indício de que as questões ambientais podem ser tratadas transversalmente em componentes curriculares integradoras.

\section{CONSIDERAÇÕES FINAIS}

Principalmente devido à sua natureza contextual, os problemas ambientais demandam uma abordagem que favoreça processos didáticos baseados no levantamento e discussão de situações significativas vivenciadas pelos sujeitos. ${ }^{27} \mathrm{O}$ papel das componentes curriculares integradoras, em tese e dependendo do referencial pedagógico adotado, pode favorecer uma aproximação entre conhecimentos científicos, situações cotidianas e conhecimentos discentes.

Através do relato dos formadores foi evidenciado que temas ambientais, enquanto problemas contemporâneos significativos e de natureza socioambiental, estão presentes com diferentes intensidades e perspectivas nas componentes curriculares integradoras. Parece haver um reconhecimento sobre a importância em abordá-los. Todavia, o modo como alguns destes vêm buscando fazê-lo apresenta características de vínculo com um ensino em que as "questões ambientais" servem mais para ilustrar conceitos e teorias. Em outros casos, a relação entre "questões ambientais" e organização dos conteúdos disciplinares de Química parece implicar uma abordagem mais complexa, como nos casos em que docentes trabalham com o enfoque CTS e a EA. Mas há sinais de que os formadores buscam transcender visões naturalistas e apontam aspectos de ordem política, social, econômica e cultural vinculados aos problemas ambientais.

A contribuição à abordagem dos temas ambientais por parte das componentes curriculares da área de ensino de Química aparenta ser vista como de prioridade secundária em comparação a outros assuntos/temas nestas próprias componentes. Ainda que os temas ambientais tenham sido mais salientados, defendidos e correlacionados entre diferentes componentes curriculares, de acordo com o que expõem resultados de pesquisas anteriores. ${ }^{13}$ Isto pode ser um indicativo de que as questões ambientais ainda não se constituem um tema nuclear das componentes curriculares integradoras na licenciatura. Todavia, não se desconsidera que em outras componentes curriculares tais questões podem estar sendo abordadas. Algo que pode ser estudado futuramente com os resultados complementares desta pesquisa. Ainda que a análise das informações permita estas interpretações, é necessário remeter às discussões envolvendo a relação entre currículo oculto e oficial. O objetivo do trabalho não foi propriamente analisar os currículos, mas compreender como componentes curriculares integradoras de cursos de licenciatura em Química podem estar colaborando para a abordagem de questões ambientais no ensino de Química. De tal sorte que o exposto sinaliza possíveis compreensões sobre as contribuições das componentes curriculares integradoras ao alcance de uma formação química preocupada com o meio ambiente.

\section{AGRADECIMENTOS}

Ao CNPq, aos colegas F. B. Roloff, F. Drews, R. H. Lindemann, S. F. Yunes e V. G. Zuin e aos docentes que participaram da pesquisa.

\section{REFERÊNCIAS}

1. Brasil; Programa nacional de educação ambiental, MEC/MMA: Brasília, 2005.

2. Machado, A. S. C.; Quim. Nova 2011, 34, 535.

3. Zuin, V. G.; Farias, C. R.; Freitas, D. A.; Revista Eletrónica de Enseñanza de las Ciências 2009, 8, 552.

4. Marques, C. A.; Gonçalves, F. P.; Zampiron, E.; Coelho, J. C.; Mello, L. C.; Oliveira, P. R. S.; Lindemann, R. H.; Quim. Nova 2007, 30, 2043.

5. Brasil, Ministério da Educação; Parâmetros Curriculares Nacionais Ensino Médio, MEC/SEB: Brasília, 2000.

6. Brasil; Orientações educacionais complementares aos Parâmetros Curriculares Nacionais: Ciências da Natureza, Matemática e suas Tecnologias, MEC/SEMTC: Brasília, 2002.

7. Santos, W. L. P. dos; Mortimer, E. F.; Investigações em Ensino de Ciências 2009, 14, 191.

8. Brasil, Conselho Nacional de Educação; Resolução $C N E / C P n^{\circ} 1$, de 18 de fevereiro de 2002.

9. Shulman, L.; Educational Research 1986, 15, 4.

10. Zuin, V. G.; Pacca, J. L.; Enseñanza de las Ciencias 2009, vol. extra, 2330 .

11. Melo, M. R.; Villani, A.; Anais do V Encontro Nacional de Pesquisa em Educação em Ciências, Bauru, Brasil, 2005.

12. Pereira, J. B.; Campos, M. L. A. M.; Nunes, S. M. T. M.; Abreu, D. G.; Quim. Nova 2009, 32, 511 .

13. Leal, A. L.; Marques, C. A.; Química Nova na Escola 2009, 29, 30.

14. Zuin, V. G.; A inserção da dimensão ambiental na formação de professores de Química, Editora Átomo: Campinas, 2011.

15. Porto Alves, P.; Corio, P.; Maximiano, F.; Fernandez, C.; Enseñanza de las Ciências 2009, vol. extra, 1527.

16. Moraes, R.; Galiazzi, M. C.; Análise Textual Discursiva, Ed. Unijuí: Ijuí, 2007. 
17. Auler, D.; Dalmolin, A. M. T.; Fenalti, V. S.; Alexandria: Revista de Educação em Ciências e Tecnologia 2009, 2, 67.

18. Brasil, Ministério da Educação; Orientações Curriculares para o Ensino Médio, MEC: Brasília, 2008.

19. Freire, P.; Pedagogia do oprimido, $25^{\mathrm{a}}$ ed., Paz e Terra: Rio de Janeiro, 1998.

20. Coelho, J. C.; Marques, C. A.; Delizoicov, D.; Anais do VII Encontro Nacional de Pesquisa em Educação em Ciências, Florianópolis, Brasil, 2009.

21. Auler, D.; Delizoicov, D.; Revista Electrónica de Enseñanza de las Ciencias 2006, 5, 337.

22. Gonçalves, F. P.; Marques, C. A.; Quim. Nova 2011, 34, 899.

23. Brasil, Ministério da Educação; Parecer CNE/CES 1.303, 2001.

24. Santos, W. P.; Galiazzi, M. C.; Pinheiro Jr., E. M.; Souza, M. L.; Portugal, S. Em Ensino de Química em Foco; Santos, W. L. P.; Maldaner, O. L, eds.; Ed. Unijuí: Ijuí, 2010, cap. 5.

25. Bazzo, W. A.; Linsingen, I. V.; Pereira, L. T. V.; Introdução aos Estudos CTS, ed. Madrid: OEI, 2003.
26. Carvalho, I. C. M.; Educação ambiental: a formação do sujeito ecológico, $3^{\mathrm{a}}$ ed., Cortez: São Paulo, 2008.

27. Coelho, C. A.; Dissertação de Mestrado, Universidade Federal de Santa Catarina, Brasil, 2005.

28. Maldaner, O. A.; Zanon, L. B. Em Educação em Ciências: Produção de Currículos e Formação de Professores; Moraes, R.; Mancuso, R., eds.; Ed. Unijuí: Ijuí, 2004, cap. 2.

29. Oliveira, H. T. de Em Vamos cuidar do Brasil: conceitos e práticas em educação ambiental na escola; Mello, S. S. de; Trajber, R., eds.; MEC/ UNESCO: Brasília, 2007, cap. 2.

30. Anastas, P. T.; Williamson, T. C.; Hjeresen, D.; Breen, J. J.; Environ. Sci. Technol. 1999, 33, 116A

31. Silva, A. F. G. da; Tese de Doutorado, Pontifícia Universidade Católica, Brasil, 2004.

32. Marques, C. A.; Gonçalves, F. P.; Fernandes, C. S.; Roloff, F. B.; Drews, F.; Silva, G. R. M. da; Yunes, S. F.; Zuin, V.; Anais do XV Encontro Nacional de Ensino de Química, Brasília, Brasil, 2010. 